\title{
$\bullet$ In-vitro Antimicrobial Analysis of the Leaf Extracts of Annonasquamosa Linn.
}

\author{
IJCRR \\ Section: Healthcare \\ ISI Impact Factor \\ (2020-21): 1.899 \\ IC Value (2020): 91.47 \\ $\operatorname{SJIF}(2020)=7.893$

\section{Samidha M. Pawaskar ${ }^{1}$, K.C. Sasangan ${ }^{2}$}

'Department of Biochemistry, K. J. Somaiya College of Science \& Commerce, Vidyavihar, Mumbai - 40o,o77, Maharashtra, India;

${ }^{2}$ K. J. Somaiya College of Science \& Commerce, Vidyavihar, Mumbai - 400,077, Maharashtra, India.

\section{ABSTRACT}

Introduction: The plant kingdom offers an infinite and therapeutic unexploited source of medicines. Various parts of some plants viz. fruits, flowers, bark, stem and roots, are seen to possess enormous bactericidal and fungicidal potential.

Aim/objective: The aim of the study was to evaluate the in vitro-antimicrobial activity of Annona squamosa Linn. leaf extract.

Methods: In-vitro antimicrobial activity of the sequential leaf extracts of Annona squamosa Linn. in different solvents like petroleum ether, chloroform, ethyl acetate, acetone, ethyl alcohol, methyl alcohol, and water, was studied against various gram-positive \& gram-negative bacterial strains using zone of inhibition.

Agar well diffusion method \& Agar disc diffusion methods were selected to evaluate the antibacterial efficacy and the minimum inhibitory concentration (MIC) of all the extracts was done using Agar well diffusion method.

The reference Antibacterial antibiotics viz., Chloramphenicol \& Ampicillin; and Antifungal antibiotics viz., Nystatin \& Clotrimazole were also tested against these standard microorganisms used in the assay and the results were compared with that of the plant extracts.

Results: The study results revealed that all the seven sequential Annona squamosa Linn. leaf extracts showed significant bactericidal and fungicidal potential against the microorganisms under study.

Highly polar solvents i.e. ethyl alcohol, methyl alcohol, and water showed the most significant antibacterial and antifungal activity against all tested organisms.

Conclusion: It can thereby be concluded that the plant material under study can be considered as a possible source of various phytochemical constituents having an in vitro antimicrobial potential.

Key Words: Annonasquamosa Linn., In-vitro antimicrobial activity, Agar well diffusion, Agar disc diffusion, Minimum inhibitory concentration (MIC), Antibacterial antibiotics, Antifungal antibiotics

\section{INTRODUCTION}

Medicinal plants have always played a governing role in the upkeeping of the human health since primordial time. ${ }^{1}$ Medicinal plants are rendered to be the best sources offering an array of novel herbal medications. ${ }^{2}$ Use of crude plant extracts as medicines although currently becoming popular all over the world, in India it was a common practice since Vedic times. Use of plant based traditional folk medicine is still a major practice in most of the developing countries including India.,

The matchless availability of the chemical diversity offered by these herbal remedies provides limitless opportunities for

\section{Corresponding Author:}

Dr. Samidha M. Pawaskar, Department of Biochemistry, K. J. Somaiya College of Science \& Commerce, Vidyavihar, Mumbai - 400077 , Maharashtra, India; Email: smpawaskar@somaiya.edu

ISSN: 2231-2196 (Print)

ISSN: 0975-5241 (Online)

Received: 05.10 .2021

Revised: 12.11 .2021 new drug formulations. Infectious diseases being amongst the prominent causes of death in the world and owing to the advent of multiple drug-resistant pathogens, researchers are now focusing their search for new, better antimicrobial compounds from plant sources. ${ }^{5,6,7}$

Annona squamosa (Annonacea) is a medium height, well branched, flower bearing shrub with sweet edible fruits. It is believed to be native of West-indies and USA. Every part of A. squamosa Linn. is claimed to possess medicinal properties viz. roots, leaves, fruits, seeds and bark.

A. squamosa leaves due to their high fiber and antioxidant content are believed to help in the regulation of blood sugar 
and quenching of free radicals, preventing cell damage. Thereby possessing anti-ageing properties. It is also believe to have anti-inflammatory properties which aids in faster healing of wounds.

Considering the aforesaid, it is believed that the need of the hour is to search for new antimicrobials. With this in mind, in the present work, the leaf extracts of Annona squamosa Linn. were screened for their probable antimicrobial activity.

\section{MATERIALS AND METHODS}

\section{In-vitro Antimicrobial Study}

\section{a. Plant Material:}

The plant material to be screened was collected from Mumbai and Talegaon - Dabhade (district - Maval, Pune). The plant sample was authenticated by the expert taxonomist of St. Xavier's College, Mumbai. (Acc.no.-102268, 00469). Matured leaves were selected for the study. The plant material was thoroughly washed, 3-4 times with tap water and once with distilled water, so as to remove all the impurities and foreign organic matter. These samples were then placed in between filter paper pads to remove maximum moisture and then shade dried in the beginning and further dried in an oven at $50-60^{\circ} \mathrm{C}$ for 25 minutes. The dried material was powdered to obtain a fine powder (mesh size $2 \mathrm{~mm}$ ) and then sieved. This was then stored in plastic containers at $4^{\circ} \mathrm{C}$ until use.

\section{b. Preparation of extract of plant leaf powder for the assay:}

The dried and finely ground leaf powder of Annona squamo$s a$ Linn., (20g each) was sequentially extracted with petroleum ether, chloroform, ethyl acetate, acetone, ethyl alcohol, methyl alcohol and water were performed using known and standardized methods. ${ }^{8}$

\section{c. Preparation of standard antibiotics solution:}

Two standard broad spectrum antibacterial antibiotics (for both gram-positive \& gram-negative bacterial strains) viz. Ampicillin (Bacteriocidal) - from Beta-Lactum medicines, Chloramphenicol (Bacteriostatic) - Other antibacterials and two commonly used antifungal antibiotics viz. Nystatin and Clotrimazol (used for fungal infections; especially for mold and yeast infections - most notably Candida) were used for the assay for comparative analysis of the leaf extract of $\mathrm{An}$ nona squamosa Linn. (According to WHO Model List of Essential medicines, $1977 ; 18^{\text {th }}$ edition $){ }^{8}$

Commercially available powdered forms of the antibiotics were dissolved in distilled water to make up standard antibiotic solutions of concentration $0.5 \mathrm{mg} / \mathrm{ml}$, (Potency specifications of antibiotics, WHO, 1997) which were further used for the assay. ${ }^{8}$

\section{d. Preparation of culture (inoculum):}

The bacterial and the fungal cultures were isolated and stored in the refrigerator and used whenever required following the known and standardized methods. ${ }^{8}$

\section{e. Preparation of culture suspension:}

Loopful of culture from the slants was suspended in small amount of nutrient broth or saline as required. ${ }^{8}$

\section{f. Agar well diffusion method:}

Agar well diffusion method was followed as standardized by Bauer and Kirby,1996 and Pawaskar and Sasangan, 2015.8,9

\section{g. Agar disc diffusion method:}

Agar disc diffusion method was followed as standardized by Bauer and Kirby,1996 and Pawaskar and Sasangan, 2015.,9

\section{h. Minimum Inhibitory Concentration:}

Minimum inhibitory concentrations i.e., the agar well containing the least concentration of the plant extract; showing inhibitory zone was performed following the standard protocol by Bauer and Kirby., 1996 and Pawaskar and Sasangan, 2015. ${ }^{8,9}$

\section{RESULT}

The percentage of extraction in various solvents for the leaf powder of Annona squamosa Linn is shown in Table-1.

The zones of inhibition for the selected organisms using sequential extracts of the leaf powders of Annona squamousa Linn. by Agar well diffusion method and Agar disc diffusion method are presented in Table- 2 and Table- 3 respectively and the minimum inhibitory concentration $(\mathrm{mg} / \mathrm{ml})$ of the leaf extracts of Annona squamosa Linn. in different solvents is presented in Table-4.

All the seven sequential extracts of the leaf powder of $\mathrm{An}$ nona squamosa Linn. exhibited prominent antimicrobial and antifungal activity against all microorganisms used in the study. In Agar well diffusion method, highly polar solvents i.e. ethyl alcohol, methyl alcohol and water exhibited the most promising antibacterial and antifungal activity against all tested organisms for the leaf extracts of Annona squamo$s a$ Linn.; with the methyl alcohol extract showing maximum inhibition in the range of $12 \mathrm{~mm}-17 \mathrm{~mm}$ for the leaf extract of Annona squamosa Linn.

Similar pattern of results was also observed in Agar disc diffusion method. Highly polar solvents i.e. ethyl alcohol, methyl alcohol and water showed the most significant antibacterial and antifungal activity against all tested organisms for the leaf extracts of Annona squamosa Linn.; with the methyl alcohol extract showing maximum inhibition in the range of $9 \mathrm{~mm}-14 \mathrm{~mm}$ for the leaf extract of Annona squamosa Linn. 
The minimum inhibitory concentration results of the leaf extracts of Annona squamosa Linn. in all the different solvents, indicated that - Salmonella typhi and Salmonella paratyphi $A$ and Pseudomonas aeruginosa were the least susceptible among the organisms tested for Annona squamosa Linn.

The results of the entire study revealed that the leaf extracts of Annona squamosa Linn. in all the different solvents used for extraction, possesses potential antimicrobial activity against the pathogens used for screening.

\section{DISCUSSION}

The effects of plant extracts on bacteria have been studied by a number of researchers in different parts of the world. Plants have been reported to possess mild to significant antimicrobial, antifungal and other activities. This has been elucidated by various workers. ${ }^{8,10,11,12,13}$

The results of the antimicrobial activity study of the leaf extract of Annona squamosa Linn. by Patel and Kumar, (2008) showed the highest zone of inhibition observed in methyl alcohol extract against $P$. aeruginosa followed by petroleum ether extract against $P$. aeruginosa and methyl alcohol extract against E. coli. ${ }^{14}$ Agar diffusion method was chosen to check antibacterial activity. However, our study showed that the maximum zone of inhibition in methyl alcohol extract was observed against Bacillus subtilis and Streptococcus pyogenes followed by Staphylococcus aureus and Vibrio cholerae. Petroleum ether extract appears to be more effective against Vibrio cholera. Escherichia coli appear to have highest susceptibility in ethyl alcoholic leaf extract of Annona squamosa Linn. Results parallel to our study have also been reported by Padhi, et al. (2011)..$^{15}$ Their screening results exhibited that highest inhibition was observed by the methyl alcohol extract followed by petroleum ether and aqueous extracts of Annona squamosa leaf. Some of the most sensitive bacterial strains used by them were, Staphylococcus aureus, Staphylococcus epidermidis, Bacillus subtilis and Vibrio alginolyticus.

\section{CONCLUSION}

In conclusion, the results of the present study have provided supportive scientific evidence that the leaf extracts of Annona squamosa Linn. possess a potential and broad spectrum of activity against a panel of bacteria. These promissory results form a primary platform for finding new clinically effective antibacterial compounds.

\section{ACKNOWLEDGEMENT}

Authors acknowledge the immense help received from the scholars whose articles are cited and included in references of this manuscript. The authors are also grateful to authors / editors / publishers of all those articles, journals and books from where the literature for this article has been reviewed and discussed.

\section{Source of funding: Nil}

Conflicts of interest: The authors declare no competing interests.

Authors' Contribution: Dr. Pawaskar has solely contributed towards the experimental work as well as the writing of this paper under the guidance and supervision of Dr. K. C. Sasangan

\section{REFERENCES}

1. Farombi EO. African indigenous plants with chemotherapeutic potentials and biotechnological approach to the production of bioactive prophylactic agents. African J. Biotech., 2003. 2;662671.

2. Prusti A, Mishra SR, Sahoo S. and Mishra SK. Antibacterial Activity of Some Indian Medicinal Plants. Ethnobotanical Leaflets. 2008. 12;227-230.

3. Farnsworth NR. The role of medicinal plants in drug development. In : Krogsgaard-Larsen, S., Brogger-Christense, S., Kofod, H. (Eds.). Natural Products and Drug Development. 1994. Munksgaard, Copenhagen.

4. Srivastava J, Lambert J and Vietmeyer N. Medicinal plants: An expanding role in development. World Bank Technical Paper No. WTP 320. The International Bank for Reconstruction and Development/The World Bank, Washington, DC., USA. April 1996. 1-36.

5. Westh H, Zinn CS, Rosdahl VT. An international multicenter study of antimicrobial consumption and resistance in Staphylococcus aureus isolates from 15 hospitals in 14 countries. Microb. Drug Resist. 2004. 10;169-176.

6. Monroe S, Polk R. Antimicrobial use and bacterial resistance. Curr. Opin. Microbiol. 2000.3; 496-501.

7. Benkeblia N. Antimicrobial activity of essential oil extracts of various onions (Allium cepa) and garlic (Allium sativum). Lebensm-Wiss u-Technol. 2004. 37;263-268.

8. Pawaskar SM and Sasangan KC. In vitro antimicrobial activity of cynodon dactylon (1.) Pers. Leaf extracts. Antimicrobial activity by zone of inhibition estimation. Indian Drugs. 2015. 52(04);37-41.

9. Bauer AW, Kirby WMM and Sherris JC. Antibiotic susceptibility testing by a standardized single disk method. Am. J. Clin. Pathol. 1996. 45;493-496.

10. Sasidharan VK, Krishnakumar T and Manjula, CB. Antimicrobial Activity of Nine Common Plants in Kerala, India. PJS. 1998. 127(1);59-67.

11. Pawaskar SM and Kale K. Antibacterial activity of sequential extracts of Mimosa pudica. Indian drugs. 2006. 43(6);476-480.

12. SudharameshwariK and Radhika J. Antibacterial screening of Aeglemarmelos, Lawsonia inermis and Albizzialibbeck. African J Trad, Complementary and Alt Med. 2007. 4(2);205-210.

13. Ramya S, Govindaraji V, Kannan NK and Jayakumararaj R. In vitro evaluation ofantibacterial activity using crude extracts of Catharanthus roseus L. (G.) Don. Ethnobotanical Leaflets. 2008. 12;1013-1018. 
14. PatelJ and Kumar V. Annona squamosa: Phytochemical analysis and Antimicrobial Screening. J of Pharmacy Res. 2008. 1(1);3438.

15. Padhi LP, Panda SK, Satapathy SN and Dutta SK. In vitro evaluation of antibacterial potential of Annona squamosa and Annona reticulate L. from Similipal. Biosphere Reserve, Orissa, India. J of Agricultural Tech. 2011. 7(1);133-142.

Table 1: Percentage of extraction in various solvents for the leaf powder of Annonasquamosa Linn.

\begin{tabular}{llc} 
Sr. No. & Solvent & \% Extracted \\
1. & Water & $32.51+1.98$ \\
2. & Methyl alcohol & $28.67+0.93$ \\
3. & Ethyl alcohol & $24.52+1.53$ \\
4. & Acetone & $16.93+2.47$ \\
5. & Ethyl acetate & $12.40+1.22$ \\
6. & Chloroform & $19.12+0.84$ \\
7. & Petroleum ether & $9.35+1.78$ \\
\hline
\end{tabular}

*All values are expressed as mean \pm SD for three determinations

Table 2: The zones of inhibtion for organisms with sequential extracts of the leafPowder of Annonasquamosa Linn. (By Agar well diffusion Method)

\begin{tabular}{|c|c|c|c|c|c|c|c|c|c|c|c|}
\hline Micro-organisms & PE & CL & EA & $\mathrm{AC}$ & ET & ME & WT & AMP & CLP & NYT & CLZ \\
\hline E.coli & 11 & 11 & 10 & 11 & 13 & 12 & 11 & - & 13 & - & - \\
\hline Proteus vulgaris & - & - & - & - & 13 & 12 & 11 & - & 15 & - & - \\
\hline Staph. aureus & 12 & 13 & 11 & 12 & 16 & 15 & 13 & 22 & - & - & - \\
\hline Klebsiellapneumoniae & 11 & 12 & 10 & 11 & 14 & 13 & 12 & - & 19 & - & - \\
\hline Pseudomonas aeruginosa & 11 & 12 & 10 & 11 & 12 & 12 & 14 & - & 16 & - & - \\
\hline Shigellaflexneri & 11 & 12 & 10 & 11 & 11 & 12 & 12 & - & 19 & - & - \\
\hline S.typhi & 09 & 10 & 09 & 10 & 13 & 12 & 14 & - & 20 & - & - \\
\hline S.paratyphi A & 10 & 12 & 10 & 11 & 14 & 13 & 12 & - & 21 & - & - \\
\hline S.paratyphi B & 11 & 12 & 10 & 11 & 14 & 13 & 12 & - & 12 & - & - \\
\hline Bacillus subtilis & 12 & 13 & 11 & 13 & 14 & 17 & 13 & - & 15 & - & - \\
\hline Strep. pyogenes & 12 & 13 & 11 & 12 & 14 & 16 & 10 & - & 18 & - & - \\
\hline Vibrio cholerae & 14 & 12 & 11 & 12 & 12 & 15 & 11 & - & 17 & - & - \\
\hline Enterobacteraerogenes & 12 & 13 & 11 & 13 & 13 & 15 & 16 & - & 18 & - & - \\
\hline Candida albicans & 11 & 13 & 12 & 11 & 13 & 14 & 12 & - & - & 26 & 30 \\
\hline S. cerevicae & 12 & 14 & 11 & 12 & 13 & 15 & 11 & - & - & 26 & 30 \\
\hline
\end{tabular}

(Note: “-” means - Zone of inhibition was not seen.)

In the table: PE: Pet ether extract; CL: Chloroform extract; EA: Ethyl acetate extract; AC: Acetone extract; ET: Ethyl alcohol extract; ME: Methyl alcohol extract; WT: Water extract; AMP: Ampicillin; CLP: Chloramphenicol; NYT: Nystatin and CLZ: Clotrimazol. 
Table 3: The zones of inhibtion for organisms with sequential extracts of the leaf powder of Annonasquamosa Linn. (By Agar disc diffusion Method)

\begin{tabular}{lccccccccccc} 
Micro-organisms & PE & CL & EA & AC & ET & ME & WT & AMP & CLP & NYT & CLZ \\
E.coli & 09 & 09 & 08 & 09 & 12 & 09 & 10 & - & 11 & - & - \\
Proteus vulgaris & - & - & - & - & 12 & 10 & 11 & - & 15 & - & - \\
Staph. aureus & 12 & 12 & 11 & 11 & 13 & 13 & 13 & 13 & - & - & - \\
Klebsiella pneumoniae & 09 & 10 & 08 & 09 & 12 & 11 & 11 & - & 19 & - & - \\
Pseudomonas aeruginosa & 10 & 10 & 10 & 10 & 11 & 11 & 12 & - & 14 & - & - \\
Shigella flexneri & 11 & 11 & 09 & 10 & 11 & 11 & 11 & - & 18 & - & - \\
S. typhi & 09 & 09 & 08 & 09 & 11 & 10 & 12 & - & 17 & - & - \\
S. paratyphi A & 10 & 10 & 09 & 10 & 11 & 10 & 11 & - & 14 & - & - \\
S. paratyphi B & 09 & 10 & 08 & 10 & 12 & 11 & 11 & - & 12 & - & - \\
Bacillus subtilis & 12 & 12 & 11 & 12 & 13 & 14 & 13 & - & 14 & - & - \\
Strep. pyogenes & 12 & 12 & 11 & 11 & 13 & 14 & 08 & - & 16 & - & - \\
Vibrio cholerae & 12 & 12 & 11 & 12 & 13 & 13 & 10 & - & 14 & - & - \\
Enterobacter aerogenes & 10 & 11 & 09 & 11 & 11 & 12 & 13 & - & 15 & - & - \\
Candida albicans & 09 & 11 & 10 & 09 & 11 & 12 & 10 & - & - & 18 & 23 \\
S. cerevicae & 10 & 12 & 09 & 10 & 11 & 13 & 09 & - & - & 19 & 25 \\
\hline
\end{tabular}

(Note: “-" means - Zone of inhibition was not seen.)

In the table: PE: Pet ether extract; CL: Chloroform extract; EA: Ethyl acetate extract; AC: Acetone extract; ET: Ethyl alcohol extract; ME: Methyl alcohol extract; WT: Water extract; AMP: Ampicillin; CLP: Chloramphenicol; NYT: Nystatin and CLZ: Clotrimazol.

Table 4: The minimum inhibitory concentrations $(\mathrm{mg} / \mathrm{ml})$ of the leaf extract of Annonasquamosa Linn. in different solvents.

\begin{tabular}{lccccccccccc} 
Micro-organisms & PE & CL & EA & AC & ET & ME & WT & AMP & CLP & NYT & CLZ \\
E.coli & 11 & 14 & 11 & 12 & 12 & 15 & 13 & - & 13 & - & - \\
Proteus vulgaris & 08 & 11 & 09 & 10 & - & - & - & - & 15 & - & - \\
Staph. aureus & 08 & 10 & 13 & 11 & 10 & 14 & 11 & 22 & - & - & - \\
Klebsiella pneumoniae & 09 & 10 & 09 & 10 & - & - & - & - & 19 & - & - \\
Pseudomonas aeruginosa & 08 & 10 & 11 & 09 & 11 & 13 & 12 & - & 16 & - & - \\
Shigella flexneri & 08 & 11 & 08 & 10 & 11 & 15 & 13 & - & 19 & - & - \\
S. typhi & 11 & 12 & 13 & 11 & 12 & 18 & 13 & - & 20 & - & - \\
S. paratyphi A & 11 & 13 & 14 & 10 & 11 & 14 & 12 & - & 21 & - & - \\
S. paratyphi B & 12 & 12 & 14 & 11 & 10 & 14 & 12 & - & 12 & - & - \\
Bacillus subtilis & 11 & 12 & 11 & 12 & 11 & 13 & 12 & - & 15 & - & - \\
Strep. pyogenes & 11 & 12 & 11 & 11 & 11 & 14 & 12 & - & 18 & - & - \\
Vibrio cholerae & 12 & 12 & 11 & 10 & 10 & 14 & 11 & - & 17 & - & - \\
Enterobacter aerogenes & 10 & 13 & 11 & 10 & 12 & 15 & 13 & - & 18 & - & - \\
Candida albicans & 10 & 13 & 10 & 12 & 12 & 14 & 11 & - & - & 26 & 30 \\
S. cerevicae & 11 & 12 & 12 & 11 & 11 & 14 & 12 & - & - & 26 & 30 \\
\hline Note: & & & & & &
\end{tabular}

(Note: “-” means - Zone of inhibitionwas not seen.)

In the table: PE: Pet ether extract; CL: Chloroform extract; EA: Ethyl acetate extract; AC: Acetone extract; ET: Ethyl alcohol extract; ME: Methyl alcohol extract; WT: Water extract; AMP: Ampicillin; CLP: Chloramphenicol; NYT: Nystatin and CLZ: Clotrimazol. 